\title{
Caracterización morfológica y molecular de materiales de yacón (Smallanthus sonchifolius Poep. \& Endl) H. Robinson colectados en la ecorregión Eje Cafetero de Colombia
}

\author{
Morphological and molecular characterization of \\ yacon materials (Smallanthus sonchifolius Poep. \& \\ Endl) H. Robinson collected in the Eje Cafetero de \\ Colombia (Colombian Coffee zone) ecoregion
}

\author{
Caracterização morfológica e molecular de materias de \\ Yacon (Smallanthus sonchifolius Poep.e Endl) H. Robinson \\ coletados na ecoregião do meio cafeeiro da Colômbia.
}

\author{
Manuel Francisco Polanco Puerta1 \& Mario Augusto García ${ }^{2}$ \\ ${ }^{1}$ Ingeniero Agrónomo, Especialista Internacional en Fruticultura (cítricos), Magister en Ciencias \\ Agrícolas, Estudiante del doctorado en Desarrollo Sostenible: Economía, Sociedad y Medio \\ Ambiente en la Universidad Católica de Ávila (España). ${ }^{2}$ Ingeniero Agrónomo, Magister en \\ Producción Vegetal con Énfasis en Mejoramiento, Doctor en Ciencias Agropecuarias \\ 'Escuela de Ciencias Agrícolas Pecuarias y del Medio Ambiente, Universidad Nacional \\ Abierta y a Distancia. Dosquebradas - Risaralda, Colombia. Bogotá, Colombia. \\ ${ }^{2}$ Facultad de Ciencias Agropecuarias, Universidad Nacional de Colombia-Sede Palmira.
}

${ }^{1}$ manuel.polanco@unad.edu.co, ${ }^{2}$ magarciad@unal.edu.co

\begin{abstract}
Resumen
El yacón (Smallanthus sonchifolius Poep. Z\& Endl) H. Robinsón, es una Asteraceae originaria de la región Andina. Es una planta utilizada por las culturas antepasadas como una fruta refrescante o alimento bajo en calorías. Sus raíces están compuestas mayormente por agua (85 a 90\%). El 40 al $70 \%$ de su peso seco está en forma de frutooligosacáridos (FOS), azúcares con efectos favorables para la salud humana, y con un alto poder antioxidante, por lo que es considerado como medicinal, para tratar problemas de diabe-
\end{abstract}

tes. La alta demanda y precio del producto en el mercado nacional e internacional hacen de ésta especie una opción rentable para los agricultores de la ecorregión Eje Cafetero, que cuenta con las condiciones agroecológicas ideales para su cultivo. Sin embargo, no se conoce información precisa sobre los materiales presentes en la región, ni de sus rendimientos, lo que dificulta proponer un manejo agronómico adecuado, para optimizar su producción. Esta investigación se realizó en cinco departamentos de la ecorregión Eje Ca- 
fetero, colectando y caracterizando morfológicamente la especie. Posteriormente se realizaron evaluaciones morfoagronómicos empleando 18 descriptores cuantitativos y ocho cualitativos, y caracterización molecular con la técnica RAMs, utilizando seis iniciadores. La caracterización morfoagronómica clasificó los diez biotipos colectados en tres grupos. La caracterización molecular diferenció cuatro grupos, que guardan estrecha relación con el agrupamiento según los caracteres cualitativos encontrados. Se concluye que las accesiones del grupo uno, son las más apropiadas para la producción de tubérculos, las del grupo dos, para la producción doble propósito y el grupo tres, para la producción de hojas. El análisis de correspondencia múltiple indica que en el germoplasma existen caracteres importantes, que pueden servir para la selección de posibles parentales con caracteres cualitativos deseables para mejoradores, agricultores y consumidores.

Palabras clave: yacón, Smallanthus sonchifolius, tubérculos andinos, fructooligosacaridos, marcadores moleculares, RAMs.

\section{Abstract}

Yacon (Smallanthus sonchifolius Poep. Z \& Endl) $\mathrm{H}$. Robinson is an Asteraceae native to the Andean region. It is a plant used by antiquated cultures as a refreshing fruit or low calorie food. Its roots are composed mostly of water (85-90\%). 40 to $70 \%$ of its dry weight comes in the form of fructooligosaccharides (FOS), sugars with favorable effects on human health, and with a high antioxidant power, which is why it is considered medicinal; for the treatment of problems associated with diabetes. The high demand and price of the product in the domestic and international markets make this species a profitable option for farmers in the Eje Cafetero (Colombian Coffee) ecoregion, which has ideal agro-ecological conditions for its cultivation. However, there is neither precise information on the materials present in the region nor information on its productivity, making it difficult to propose the appropiate agronomic management to optimize its production. This research was conducted in five provinces of the Eje Cafetero ecoregion, collecting and morphologically characterizing the species. Subsequent morphoagronomic evaluations were performed using 18 quantitative descriptors, and eight qualitative ones, in addition to the molecular characterization with the RAMs technique using six initiators. The morphoagronomic characterization classified the ten collected biotypes into three groups. Molecular characterization distinguished four groups, which are closely related to the grouping according to the qualitative characteristics found. The paper concludes that the accessions of group one are the most appropriate for the production of tubers, those of group two for dualpurpose production and those of group three, for leaf production. The multiple correspondence analysis (MCA) indicates that within the germplasm there are important characters that can be used towards the selection of potential parents with desirable quality traits for breeders, farmers and consumers.

Key-words: yacon, Smallanthus sonchifolius, andean tubers, fructooligosaccharides, molecular markers, RAMs

\section{Resumo}

O yacon (Smallanthus sonchifolius Poep. Z e Endl) $H$. Robinsón, é uma Asteraceae originaria da região andina. É uma planta utilizada pelas culturas antepassadas como uma fruta refrescante e alimento de baixa caloria. Suas raízes estão compostas em sua maioridade por água (85 a $90 \%$ ). O 40 a $70 \%$ de sua matéria seca 
estão em forma de frutos oligosacaridios (FOS), açucares com efeitos favoráveis para a saúde humana, e com um alto poder antioxidante, por isso é considerado uma planta medicinal, para tratar problemas de diabetes. A alta demanda e preço do produto no mercado nacional e internacional fazem da espécie uma opção rentável para os agricultores da ecoregião do "Eje cafetero" que contam com as condições agroecológicas ideias para o seu cultivo. Contudo, não se tem conhecimento sobre a aérea cultivada na região, nem de seus rendimentos agrícolas, o que dificulta propor um manejo agronômico adequado para otimizar sua produção. Esta investigação foi realizada em 5 municípios da ecoregião do "Eje cafetero", coletando e caracterizando morfologicamente a espécie. Posteriormente se realizaram avaliações morfoagronômicas utilizando 18 descrições qualitativas e quantitativas e caracterizações mole- culares com a técnica de RAMs, utilizando seis indicadores. A caracterização morfoagronômica classificou os dez biótipos coletados nos três grupos. A caracterização molecular diferenciou quatro grupos, que guardam uma estreita relação com o agrupamento segundo as características qualitativas encontradas. Concluiu-se que as seções do grupo 1 são as mais apropriadas para a produção de tubérculos. As do grupo 2 , para a produção dupla e o grupo 3 para a produção de folhas. A análise de correspondência múltipla indica que no germosplasma existem características importantes, que podem servir para a seção de possíveis genes parentais com características qualitativas desejáveis para criadores, agricultores e consumidores.

Palabras chave: yacon, Smallanthus sonchifolius, tuberculos andinos, frutos oligossacarideos, marcadores moleculares, RAMs.

\section{Introducción}

Se ha señalado que una de las causas de la baja utilización de los recursos fitogenéticos es la falta de información sobre éstos (Ordás et al. 1994 citado por Lobo, 2006). Por ello, en la formulación del Plan Global de Acción de Recursos Fitogenéticos para la Alimentación y la Agricultura, se incluyó el incremento de las acciones de caracterización y evaluación (FAO, 1996). En el Plan se señala que la ausencia de este tipo de acciones impide el aprovechamiento del valor de la variabilidad genética, de lo cual se derivan unos costos de conservación elevados con relación a los beneficios obtenidos a partir de las colecciones.
Al yacón (Smallanthus sonchyfolia) en Colombia no se le ha dado la importancia que se merece, ni siquiera desde la medicina natural, pues no se han realizado investigaciones para conocer su diversidad genética, comportamiento agronómico, valor nutricional, como tampoco para distinguir la composición de los metabolitos secundarios, al contrario de países como Perú, y Japón. En Perú, por ejemplo, varias instituciones conservan bancos de germoplasma de esta especie con centenas de accesiones colectadas, debidamente caracterizadas morfológica y molecularmente, y en Japón se reporta que ya tienen variedades mejoradas con mayores producciones de frutoligosacáridos FOS (Hernández, 2004). 
Para Grau \& Rea (1997) esta es una planta que se adapta fácilmente a espacios libres dejados en la vegetación; esta estrategia de colonización puede ser la razón por la cual el yacón fue asociado con los primeros asentamientos humanos, cuando la agricultura incipiente de cortar y quemar, proporcionaba el nicho ideal para su establecimiento. Este comportamiento puede ser observado hoy en día en especies como S. siegesbeckius, que comúnmente invade campos abandonados de café en el Perú y por S. macroscyphus en el noreste de Argentina invadiendo campos abandonados de caña de azúcar. Al parecer existe una alta posibilidad que un hibrido de dos o más especies de Smallanthus colonizadoras de hábitats disturbados, dieran lugar a una especie ancestral del yacón.

Es muy probable que en las tempranas etapas, campesinos de los Andes descubrieran las propiedades del yacón y le cambiaron el estatus de mala hierba a una planta manejable y más tarde a cultivable. El área más probable en donde pudieron suceder esos eventos, son las laderas húmedas de los Andes occidentales, en la región comprendida entre el noreste de Bolivia y el centro de Perú, el área con la mayor diversidad de clones y en donde la lengua nativa Quechua y Aymara nombra su uso. La diversidad es más reducida en Ecuador en donde modificaciones de la palabra xicama domina. Ambos factores puede indicar que la especie fue introducida allí en épocas posteriores, quizá con la conquista del Ecuador por parte de los Incas, solo unas décadas antes de la invasión española (Grau \& Rea, 1997).

El aspecto más llamativo de esta especie lo constituyen sus órganos subterráneos, conformados por un tronco engrosado y ramificado denominado corona, que presenta brotes cortos conocidos como propágulos o rizomas, en los cuales se almacenan sustancias de reserva en forma de carbohidratos simples y frutoligosacaridos, los cua- les posiblemente sirven de alimento a las yemas, cuando estas van a brotar.

A los rizomas también están unidas las raíces, las cuales son de dos tipos: las fibrosas, delgadas y absorbentes que pueden alcanzar en promedio $60 \mathrm{~cm}$ de profundidad, y las raíces tuberosas, generalmente fusiformes, almacenadoras y de gran tamaño, con dimensiones que pueden sobrepasar los $25 \mathrm{~cm}$ largo y $10 \mathrm{~cm}$ de espesor. A diferencia de otras raíces de este tipo, su composición es un alto porcentaje de agua (70 - 90\%) y azúcares del tipo frutanos en lugar de almidón. La coloración de la epidermis varia del rojizo a blanco y la pulpa puede ser blanca, cremosa a morada, ver Figura 5 (Seminario et al. 2003).

Se ha reportado que las raíces y el jarabe de yacón tienen efectos significativos en la reducción de los niveles de glucosa en la sangre en personas clínicamente sanas (Mayta et al., 2003) y en personas con diabetes tipo 2. Estas evidencias son reforzadas con resultados similares obtenidas en animales de laboratorio a los que se les indujo diabetes (Galindo \& Paredes, 2002; Rodríguez \& Soplopuco, 2004 citados por Manrique et al., 2005). Aunque resulta prematuro que el jarabe de yacón sea benéfico para el control de la diabetes, hay un camino que se ha abierto para la investigación en este campo que pronto podría dar las evidencias definitivas que se necesitan para recomendar su consumo en personas con diabetes (Manrique et al., 2005).

Considerando: 1) la gran demanda de países como Estados Unidos, Canadá y el mercado nacional, por los componentes químicos presentes en las raíces, y hojas del yacón, 2) que la especie ya se encuentra cultivada en algunos predios de los agricultores, 3) que las características agroecológicas de la ecorregión Eje Cafetero, la hacen apta para establecer cultivos de yacón, como una excelente alternativa de producción, este documento pretende establecer las bases del conocimiento de su 
variabilidad genética presente en esta región, que puedan sostener científicamente su potencial de desarrollo agronómico y económico.

Por lo tanto, el objetivo general de este trabajo fue caracterizar morfológica y molecularmente materiales de yacón, colectados en el Eje Cafetero de Colombia, que permita conocer la variabilidad genética de esta especie en la región, para su conservación ex situ en campo, y aplicación de procesos de selección y mejoramiento genético posteriormente.

\section{Materiales y métodos}

El trabajo de caracterización morfológica y molecular de la especie yacón Smallanthus sonchifolius colectadas en la ecorregión Eje Cafetero se realizó en cuatro fases como se explica a continuación.

Primera fase: la colecta del germoplasma del yacón se realizó en fincas de agricultores ubicadas en varios municipios de los departamentos de Risaralda, Quindío, Caldas, Tolima y Norte del Valle, identificadas previamente como predios en donde se ha mantenido producción del yacón. Al momento de la colecta se realizó una descripción morfológica preliminar, con base en descriptores morfológicos propuestos por Seminario et al. (2003).

Los recursos fitogenéticos se conservan para utilizarlos, y ello solo es posible si se conocen en detalle sus características o atributos y se visualizan sus posibles usos (Jaramillo \& Baena, 2000; citados por CIAT, 2004). Para caracterizar un material vegetal es preciso recurrir al estudio de atributos morfológicos, estructurales o funcionales contenidos en el germoplasma, como portador de las características hereditarias de la especie.

Se recolectaron tres muestras por grupo representativo, de la parte reproductiva de la especie (rizomas). Se tomó información de pasaporte que incluye ubicación geográfica de la finca, nombre y dirección del agricultor, georeferenciación del sitio de colecta, datos agroecológicos del sitio y descripción morfológica de la planta.

Segunda fase: los materiales colectados se sembraron en un lote semiurbano de la Universidad Nacional Abierta y a Distancia, ubicado en el municipio de Dosquebradas Risaralda, a una altura de 1.460 m.s.n.m., con una temperatura promedio de $21^{\circ} \mathrm{C}$, una precipitación anual de $2.200 \mathrm{~mm}$ y humedad relativa de $80 \%$. La zona corresponde a bosque muy húmedo premontano (bmh-PM), según la clasificación de zona de vida de Holdridge.

Las accesiones colectadas se sembraron bajo un diseño completamente al azar con una estructura de medidas repetidas en el tiempo, en donde cada surco de la parcela correspondía a una accesión con 10 plantas. Cada planta fue una unidad experimental. Los surcos estaban a una distancia de $1.40 \mathrm{~m}$. y la distancia entre plantas fue de $1 \mathrm{~m}$.

\section{Descriptores de las fichas de caracterización}

- Ubicación de la finca: se tomaron datos para ubicación del predio de colecta, como, nombre del propietario, nombre de la vereda, del municipio y del departamento, las coordenadas geográficas, como la fecha de la colecta. Condiciones agroecológicas: se determinó la altura del predio, datos de precipitación, temperatura, humedad relativa y luminosidad fueron consultadas con el agricultor. Las características físicas del suelo como textura, estructura, permeabilidad, color, \% materia orgánica, $\mathrm{pH}, \mathrm{y}$ relieve fueron verificados en campo y con los análisis de suelo en los lugares que contaban con estos. 


\section{- Material vegetal:}

Tallo: tipo de crecimiento, forma de ramificación, longitud, diámetro, color, forma, pubescencia. Tipo de crecimiento: monopodial o simpodial, determinado o definido (o de mata baja). Forma de ramificación: determinada o indeterminada. Longitud del tallo (altura): Distancia en centímetros entre la base del tallo en el suelo y el extremo superior del tallo, (inserción de la yema terminal). El diámetro del tallo: distancia en centímetros del ancho del tallo, medido en la base del mismo. Hojas: forma, color, longitud, ancho, pubescencia, color lígula, forma de la lígula y número de hojas por tallo. Las mediciones se realizaron en el tercer par de hojas bien formadas de arriba hacia abajo. Longitud de la hoja: medición en $\mathrm{cm}$ desde la base del foliolo en el peciolo, hasta el ápice. Ancho de la hoja: medición en $\mathrm{cm}$ de la parte más ancha del foliolo, en la base del foliolo. Largo del pecíolo de la hoja: medición en cm desde el punto de inserción en el tallo a la unión con el foliolo.

Inflorescencia. Capítulo: número de capítulos por tallo, diámetro del capítulo, número de flores masculinas y femeninas, número de semillas por inflorescencia, color.

Tubérculos: número de tubérculos por planta, peso total de tubérculos por planta, peso de cada tubérculo, longitud de tubérculos, diámetro de tubérculo, color externo, color pulpa, consistencia, color propágulo, cantidad de propágulos.

Semillas: Peso de 100 semillas, color semilla, porcentaje de germinación.

Tercera fase: caracterización molecular, para la extracción del ADN, se emplearon hojas jóvenes frescas, colectadas en la mañana, de cada una de las accesiones de yacón; se utilizó el kit de extracción PowerPlant ${ }^{\circledR}$ empleando 50 mg de tejido vegetal de cada accesión. Este se maceró con nitrógeno líquido hasta obtener un polvo fino y seco, al que posteriormente se le aplicaron los 24 pasos del protocolo del kit, hasta obtener el ADN puro para desarrollar la técnica RAMs (Random Amplified Microsatellites) o microsatélites amplificados al azar.

Los microsatélites son secuencias de una a cuatro pares de bases, repetidas muchas veces, que van seguidas de otras secuencias distintas dentro del genoma en organismos procariotes y eucariotes. Están presentes en regiones codificadoras y no codificadoras de genes, las cuales se caracterizan por tener un alto grado de polimorfismo (Ferreira \& Grattapaglia, 1998)

La base genética de los RAMS es la misma que la de los RAPDs (por Random Amplified Polymorphic DNA). Utiliza un solo primer de secuencia arbitraria, por lo cual la secuencia blanco también es desconocida. Difiere de los RAPDs en el tamaño del primer, ya que la secuencia nucleótidica en los RAMS es más grande y además posee un sitio "degenerado" de tres nucleótidos cuya función es asegurar el anclaje del primer a la región microsatélite. Igualmente, ambos detectan un solo alelo por locus (Muñoz et al., 2009).

Este método es el que suministra el más elevado contenido de información de polimorfismo. En síntesis, los microsatélites se han convertido en una técnica casi obligatoria en los estudios genéticos, pero algunos aspectos como su aislamiento siguen abiertos a la investigación. Los protocolos de trabajo siguen actualizándose constantemente, particularmente en la Universidad Nacional de Colombia Sede Palmira, se han realizado varios trabajos de caracterización molecular con mora (Rubus spp), uchuva (Physalis peruviana L), guayaba (Psidium guajava), y heliconias (Heliconia Spp), optimizándose el proceso (Muñoz et al, 2009).

\section{Iniciadores utilizados}

Para evaluar la diversidad genética de las muestras de ADN se probaron seis iniciadores sintetizados por Technologies Inc. En la Tabla 1 
Tabla 1. Iniciadores utilizados en la caracterización molecular de Smallanthus sonchifolios.

\begin{tabular}{lc}
\hline INICIADOR & \multicolumn{1}{c}{ SECUENCIA } \\
\hline CT & DBDCTCTCTCTCTCTCTC \\
CGA & DHBCGACGACGACGACGA \\
CA & DBDACACACACACACACACA \\
AG & HBHAGAGAGAGAGAGAGAG \\
TG & HVHTGTGTGTGTGTGTGT \\
CCA & DDBCCACCACCACCA \\
\hline
\end{tabular}

Análisis de la información obtenida en la caracterización morfoagronómica

Cuarta Fase: se realizó el análisis descriptivo para cada uno de los caracteres cuantitativos.

Para el pool de variables conformado por los caracteres morfoagronómicos agrupados en los tres grupos, se efectuó un análisis de clúster vía análisis de componentes principales. También se realizó un análisis factorial en el cual se enfatizaron los aportes porcentuales de cada una de las variables sobre los ejes factoriales. Para el análisis de la información obtenida de los caracteres cualitativos, se utilizó el análisis de correspondencia múltiple. Los análisis de los datos se realizaron utilizando el paquete estadístico SAS® (Statistical Analysis System versión 9.2).

\section{Análisis de la información obtenida por la técnica molecular}

Para el análisis de la información de la variabilidad genética obtenida por la técnica molecular de RAMs se construyó una matriz de variables binarias, con ceros (ausencia de bandas) y unos (presencia de bandas) en la cual las accesiones forman las filas y las columnas las bandas evalua- das en cada uno de ellos. Esta matriz se analizó con el programa SIMQUAL del paquete "Numerical Taxonomy System for Personal Computer" (NTSYS-pc versión 1.8).

El dendograma se construyó con base en los grados de similaridad entre individuos.

\section{Resultados y discusión}

Las condiciones agroecológicas reinantes en los sitios donde se realizó la colecta de los materiales se presentan en la Tabla 2, en esta se puede observar, que los agricultores de la región han establecido la especie en diferentes condiciones agroecológicas, la cual se adaptó satisfactoriamente. La altura menor de colecta fue 1.120 m.s.n.m., en la finca La Alameda, cerca a la ciudad de Ibagué y la más alta, los 2.423 m.s.n.m., en la Reserva Natural Acaime, Salento, Quindío.

Las características físicas del suelo de los sitios, demuestran que la especie se adapta muy bien a los suelos de textura franco arcillosos a francos arenosos. También se concluye que los agricultores la han establecido en terrenos planos, ondulados y la gran mayoría en terrenos fuertemente inclinados, con suelos medianamente profundos a profundos, con buen contenido de materia orgánica.

Todas las muestras colectadas de yacón presentan hojas de forma triangular, con ápice acuminado, borde aserrado, más anchas que largas, con una gran área foliar. Las mayores variaciones encontradas con respecto a la hoja fueron en un material de lbagué, que presenta base truncada en lugar de hastada (Figura 6) y color de hojas entre verde claro al verde oscuro. También se observa mayor área foliar en las plantas ubicadas en las zonas más frías y con menos horas de brillo solar, que en las cálidas y con mayor luminosidad. 
Tabla 2. Características agroecológicas de las fincas de colecta S. sonchifolius

\begin{tabular}{lccccc}
\hline \multicolumn{1}{c}{ LOCALIDAD } & $\begin{array}{c}\text { Altura } \\
\text { (m.s.n.m) }\end{array}$ & $\begin{array}{c}\text { Temperatura } \\
\left.\text { promedio ( }{ }^{\mathrm{C}} \mathbf{C}\right)\end{array}$ & $\begin{array}{c}\text { Precipitación } \\
(\mathbf{m m} \text { anuales) }\end{array}$ & $\begin{array}{c}\text { Humedad } \\
\text { Relativa (\%) }\end{array}$ & $\begin{array}{c}\text { Luminosidad } \\
\text { (horas/dia) }\end{array}$ \\
\hline Sta. Rosa de Cabal & 1640 & 20 & 2200 & 80 & 6 \\
\hline Pereira & 2072 & 16 & 2700 & 85 & 4 \\
Calarcá & 1260 & 20 & 2200 & 85 & 5 \\
\hline Salento & 2423 & 18 & 2500 & 80 & 5 \\
\hline Neira & 1693 & 20 & 1800 & 80 & 6 \\
\hline Rio Sucio & 1250 & 28 & 2000 & 80 & 6 \\
\hline El Dovio & 1518 & 20 & 2000 & 80 & 6 \\
\hline Trujillo & 1588 & 20 & 2000 & 80 & 6 \\
Ibagué & 1120 & 22 & 1050 & 60 & 8 \\
\hline Palocabildo & 1444 & 20 & 2300 & 80 & 6 \\
\hline
\end{tabular}

En la Tabla 3 se incluye la información de promedios, valores máximos y mínimos obtenidos con las características cuantitativas registradas en el estudio. Todos los atributos exhibieron variabilidad.

En el análisis de correlación (Tabla 4), se observa que el número y el diámetro de los tubérculos de raíz, ( $r=0.8382,0.8654$ respectivamente) son los caracteres que más contribuyeron positivamente con la ganancia de un mayor peso de los tubérculos de raíz. En cambio, aquellos relacionados con la exuberancia de la planta, como número de ramas, número de hojas/rama, ancho de la hoja, largo de la hoja, y producción de capítulos florales, son los que más influyen negativamente sobre el peso final de los tubérculos. Estas accesiones pueden ser consideradas para programas en los que se pretenda producir hojas, para la alimentación animal, o para la fabricación de medicamentos a base de hojas. En éste análisis de correlación se puede inferir relaciones directas e inversamente proporcionales entre el peso del tubérculo y las variables pero no se puede asegurar que disminuir el número de ramas aumente el peso del tubérculo. 
Tabla 3. Resultados descriptivos para cada una de las variables cuantitativas registradas en la colección de yacón, Smallanthus sonchifolios.

\begin{tabular}{|c|c|c|c|c|}
\hline VARIABLES & Media & Valor Mínimo & Valor Máximo & D.S. \\
\hline No. tubérculos de raíces & 10.37 & 4.75 & 13.5 & 2.456 \\
\hline Peso tubérculo de raíz (g) & 3619 & 744.25 & 5363 & 1742 \\
\hline Longitud tubérculo (cm) & 17.30 & 15.78 & 18.10 & 0.658 \\
\hline Diámetro tubérculo $(\mathrm{cm})$ & 4.98 & 3.58 & 3.05 & 0.977 \\
\hline No. capítulos & 205.17 & 89.30 & 623.90 & 167.72 \\
\hline No. flores femeninas & 14.12 & 13.70 & 15.0 & 0.413 \\
\hline No. flores masculinas & 72.64 & 59.80 & 82.50 & 7.846 \\
\hline Peso de 100 semillas & 0.591 & 0.493 & 0.771 & 0.088 \\
\hline Altura $(\mathrm{cm})$ & 136.8 & 112.20 & 157.30 & 15.23 \\
\hline Diámetro tallo $(\mathrm{cm})$ & 3.76 & 3.4 & 4.34 & 0.311 \\
\hline No. ramas & 19.62 & 15.00 & 28.00 & 3.613 \\
\hline No. hojas /tallo & 16.96 & 7.60 & 24.00 & 5.648 \\
\hline No. hojas/rama & 8.90 & 7.60 & 11.60 & 1.200 \\
\hline Ancho hoja (cm) & 23.75 & 18.90 & 29.40 & 3.199 \\
\hline Largo hoja $(\mathrm{cm})$ & 20.35 & 16.40 & 24.10 & 2.440 \\
\hline Largo peciolo $(\mathrm{cm})$ & 12.36 & 9.5 & 16.60 & 2.223 \\
\hline Largo entrenudos (cm) & 11.42 & 9.40 & 14.40 & 1.633 \\
\hline No. hojas caídas & 16.42 & 13.80 & 18.00 & 1.488 \\
\hline
\end{tabular}

*D.S. = desviación estándar. 
Tabla 4. Correlación del peso de los tubérculos de raíz (niveles de significancia) vs variables morfológicas del yacón.

\begin{tabular}{lccrrrr}
\hline & $\begin{array}{c}\text { No. tubér- } \\
\text { culo de raíz }\end{array}$ & $\begin{array}{c}\text { Peso } \\
\text { tubérculo } \\
\text { de raíz }\end{array}$ & $\begin{array}{c}\text { Longitud } \\
\text { tubérculo } \\
\text { de raíz }\end{array}$ & $\begin{array}{c}\text { Diámetro } \\
\text { tubérculo } \\
\text { de raíz }\end{array}$ & $\begin{array}{c}\text { No. de } \\
\text { capítulos }\end{array}$ & $\begin{array}{c}\text { No. flores } \\
\text { femeninas }\end{array}$ \\
$\begin{array}{l}\text { Peso Tubérculo } \\
\text { de raíz }\end{array}$ & $\begin{array}{l}0.83821 \\
(0.0025)\end{array}$ & 1.0000 & $\begin{array}{c}0.41420 \\
(0.2340)\end{array}$ & $\begin{array}{l}0.86543 \\
(0.0012)\end{array}$ & $\begin{array}{r}-0.72890 \\
(0.0168)\end{array}$ & $\begin{array}{l}0.12183 \\
(0.7373)\end{array}$ \\
\hline
\end{tabular}

\begin{tabular}{lrrrrrr}
\hline & $\begin{array}{c}\text { No.flores } \\
\text { masculinas }\end{array}$ & $\begin{array}{c}\text { Peso 100 } \\
\text { semillas }\end{array}$ & $\begin{array}{c}\text { Longitud } \\
\text { tallo }\end{array}$ & $\begin{array}{c}\text { Diámetro } \\
\text { tallo }\end{array}$ & No. ramas & $\begin{array}{c}\text { No. hojas } \\
\text { tallo ppal. }\end{array}$ \\
\hline $\begin{array}{l}\text { Peso Tubérculo } \\
\text { de raíz }\end{array}$ & 0.37176 & 0.58658 & -0.50293 & -0.03222 & -0.67063 & -0.10553 \\
\hline
\end{tabular}

\begin{tabular}{lccccrr}
\hline & $\begin{array}{c}\text { No. hojas/ } \\
\text { rama }\end{array}$ & $\begin{array}{l}\text { Ancho } \\
\text { hoja }\end{array}$ & \multicolumn{1}{c}{$\begin{array}{c}\text { Largo } \\
\text { hoja }\end{array}$} & $\begin{array}{c}\text { Largo } \\
\text { peciolo }\end{array}$ & $\begin{array}{c}\text { Largo } \\
\text { entrenudos }\end{array}$ & \multicolumn{1}{c}{$\begin{array}{c}\text { No. hojas } \\
\text { caídas }\end{array}$} \\
\hline Peso tubérculo & -0.72200 & -0.64333 & -0.58130 & -0.54820 & -0.47026 & -0.21497 \\
de raíz & $(0.0184)$ & $(0.0448)$ & $(0.0780)$ & $(0.1009)$ & $(0.1702)$ & $(0.5509)$ \\
\hline
\end{tabular}

En los resultados de la prueba Duncan del grupo de caracteres morfoagronómicos relacionados con el desarrollo vegetativo de la planta de cada una de las accesiones en las diferentes épocas de muestreo, todos presentaron diferencias altamente significativas $(P<0.01)$ En Tabla 5 se presenta las diferencias por descriptor y para cada accesión evaluada.

Se encontraron diferencias mínimas significativas para el largo del tallo principal entre las accesiones, siendo la accesión Trujillo (Valle del Cauca), el de mayor altura promedia, seguida por Salento
(Quindío). Sin embargo es ésta la que logra la mayor altura al final de su desarrollo vegetativo, con $1.57 \mathrm{~m}$. La plantas más bajas son las accesiones de El Dovio (Valle del Cauca), Ibagué (Tolima) y Calarcá (Quindío), con $1.12 \mathrm{~m}$. al final del desarrollo (Tabla 5 y Figura 7).

Al evaluar el diámetro del tallo, la accesión de Trujillo (Valle del Cauca) es la de mayor diámetro y las de Pereira y Santa Rosa de Cabal (Risaralda) las más delgadas. El diámetro de todas las accesiones aumentó constantemente con el paso de los días, hasta un máximo de $4.5 \mathrm{~cm}$. Ver Figura 8 . 
Tabla 5. Comparaciones de la prueba DUNCAN entre los diferentes caracteres morfoagronómicos cuantitativos, evaluados para cada uno de las accesiones de S. sonchifolius

\begin{tabular}{lccccccccccc}
\hline & \multicolumn{7}{c}{ Promedios Descriptor } \\
\cline { 2 - 10 } Accesión & $\begin{array}{l}\text { Largo } \\
\text { tallos }\end{array}$ & $\begin{array}{c}\text { Diámetro } \\
\text { Tallo }\end{array}$ & $\begin{array}{c}\text { No. } \\
\text { ramas }\end{array}$ & $\begin{array}{c}\text { No. } \\
\text { hojas } \\
\text { tallo }\end{array}$ & $\begin{array}{c}\text { No. } \\
\text { hojas } \\
\text { rama }\end{array}$ & $\begin{array}{c}\text { Ancho } \\
\text { hoja }\end{array}$ & $\begin{array}{c}\text { Largo } \\
\text { hoja }\end{array}$ & $\begin{array}{c}\text { Largo } \\
\text { peciolo }\end{array}$ & $\begin{array}{c}\text { Largo } \\
\text { entrenudo }\end{array}$ & $\begin{array}{c}\text { Hojas } \\
\text { caída }\end{array}$ \\
\hline TRUJILLO-VAL & $77.9 \mathrm{a}$ & $2.4 \mathrm{a}$ & $10.9 \mathrm{~b}$ & $13.2 \mathrm{c}$ & $6.7 \mathrm{~b}$ & $23.3 \mathrm{~b}$ & $19.7 \mathrm{~d}$ & $12.0 \mathrm{~b}$ & $7.7 \mathrm{a}$ & $10.4 \mathrm{a}$ \\
\hline SALENTO-QUI & $65.8 \mathrm{~b}$ & $2.1 \mathrm{c}$ & $10.1 \mathrm{c}$ & $13.5 \mathrm{cb}$ & $6.6 \mathrm{~b}$ & $25.5 \mathrm{a}$ & $21.4 \mathrm{ba}$ & $12.1 \mathrm{~b}$ & $6.9 \mathrm{c}$ & $8.7 \mathrm{c}$ \\
\hline PALOCAB-TOL & $58.2 \mathrm{c}$ & $2.3 \mathrm{~b}$ & $10.1 \mathrm{c}$ & $14.0 \mathrm{a}$ & $6.5 \mathrm{cb}$ & $24.9 \mathrm{a}$ & $21.6 \mathrm{a}$ & $11.4 \mathrm{~cd}$ & $7.8 \mathrm{a}$ & $9.8 \mathrm{~b}$ \\
\hline STA.ROSA-RIS & $55.7 \mathrm{dc}$ & $1.8 \mathrm{f}$ & $9.6 \mathrm{dc}$ & $12.3 \mathrm{~d}$ & $4.6 \mathrm{f}$ & $21.2 \mathrm{c}$ & $17.9 \mathrm{f}$ & $11.8 \mathrm{cb}$ & $6.7 \mathrm{dc}$ & $8.7 \mathrm{c}$ \\
\hline PEREIRA-RIS & $56.2 \mathrm{dc}$ & $1.9 \mathrm{e}$ & $11.8 \mathrm{a}$ & $12.2 \mathrm{~d}$ & $5.9 \mathrm{ed}$ & $23.5 \mathrm{~b}$ & $19.0 \mathrm{ed}$ & $13.2 \mathrm{a}$ & $6.6 \mathrm{~d}$ & $8.7 \mathrm{c}$ \\
\hline NEIRA-CAL & $55.8 \mathrm{~d}$ & $2.1 \mathrm{dc}$ & $9.4 \mathrm{~d}$ & $10.5 \mathrm{e}$ & $6.2 \mathrm{~cd}$ & $24.9 \mathrm{a}$ & $20.7 \mathrm{bc}$ & $12.9 \mathrm{a}$ & $6.5 \mathrm{~d}$ & $8.1 \mathrm{~d}$ \\
\hline RIOSUC-CAL & $53.3 \mathrm{e}$ & $2.1 \mathrm{~d}$ & $9.9 \mathrm{dc}$ & $10.3 \mathrm{e}$ & $5.8 \mathrm{e}$ & $23.4 \mathrm{~b}$ & $19.5 \mathrm{~d}$ & $11.4 \mathrm{cde}$ & $7.3 \mathrm{~b}$ & $7.7 \mathrm{e}$ \\
\hline DOVIO-VAL & $50.0 \mathrm{f}$ & $2.2 \mathrm{~b}$ & $11.2 \mathrm{~b}$ & $12.4 \mathrm{~d}$ & $7.0 \mathrm{a}$ & $23.5 \mathrm{~b}$ & $20.5 \mathrm{c}$ & $10.8 \mathrm{e}$ & $7.3 \mathrm{~b}$ & $6.9 \mathrm{f}$ \\
\hline IBAGUÉ-TOL & $48.1 \mathrm{f}$ & $2.0 \mathrm{~d}$ & $9.5 \mathrm{c}$ & $12.2 \mathrm{~d}$ & $6.3 \mathrm{cb}$ & $23.1 \mathrm{~b}$ & $19.0 \mathrm{ed}$ & $11.9 \mathrm{cb}$ & $6.6 \mathrm{~d}$ & $8.5 \mathrm{c}$ \\
\hline CALARCÁ-QUI & $47.9 \mathrm{f}$ & $2.0 \mathrm{~d}$ & $9.8 \mathrm{dc}$ & $13.6 \mathrm{~b}$ & $6.4 \mathrm{cb}$ & $21.3 \mathrm{c}$ & $18.7 \mathrm{e}$ & $11.0 \mathrm{de}$ & $6.8 \mathrm{dc}$ & $8.1 \mathrm{~d}$ \\
\hline
\end{tabular}

Nota: Dentro de una misma columna, promedios con igual letra no difieren estadísticamente

La accesión con mayor número de ramas es la proveniente de Pereira, seguida por la de El Dovio y Trujillo, la de menor número de ramas es la de Santa Rosa de Cabal. Las accesiones con mayor número de hojas caídas son Trujillo y Palocabildo, y las que menos hojas se le caen son las de El Dovio y Rio Sucio. Esta variable se consideró, ya que la cantidad de hojas caídas de la planta, nos puede dar una idea, de la capacidad de producción de hojas y las que realmente requiere para sostener una buena producción de tubérculo. Ver Figura 9.
El número de flores masculinas por capítulo es un descriptor que tiene gran variabilidad, entre 59.7 a 82 flores. Las accesiones de Calarcá y Palocabildo son las de menor número de flores y Santa Rosa y Trujillo las de mayor, (Tabla 6).

A pesar de que las semillas producidas por cada una de las accesiones estaban bien formadas, no eran viables, lo que se comprobó por pruebas de germinación. Las semillas producidas por Santa Rosa y Trujillo fueron las de mayor peso. Las de menor Calarcá y Palocabildo (Tabla 6). 
Tabla 6. Prueba DUNCAN, de los datos promedios de los descriptores cuantitativos relacionados con la inflorescencia, estructura floral y semillas de Smallanthus sonchifolius

\begin{tabular}{lcccc}
\hline \multicolumn{1}{c}{ ACCESIÓN } & \multicolumn{4}{c}{ PROMEDIOS DESCRIPTOR } \\
\cline { 2 - 5 } & $\begin{array}{c}\text { No. capítulos/ } \\
\text { planta }\end{array}$ & $\begin{array}{c}\text { No. flores } \\
\text { femeninas/flor }\end{array}$ & $\begin{array}{c}\text { No. flores } \\
\text { masculinas/flor }\end{array}$ & $\begin{array}{c}\text { Peso de } 100 \\
\text { semilla (g) }\end{array}$ \\
\hline STA.ROSA-RIS & $604.6 \mathrm{a}$ & $14.9 \mathrm{a}$ & $82.4 \mathrm{a}$ & $0.770 \mathrm{a}$ \\
\hline TRUJILLO-VAL & $336.0 \mathrm{~b}$ & $14.5 \mathrm{a}$ & $82.3 \mathrm{a}$ & $0.693 \mathrm{ba}$ \\
\hline PEREIRA-RIS & $241.4 \mathrm{~b}$ & $14.3 \mathrm{a}$ & $77.2 \mathrm{ba}$ & $0.622 \mathrm{bc}$ \\
\hline EL DOVIO-VAL & $158.9 \mathrm{~d}$ & $14.2 \mathrm{a}$ & $76.9 \mathrm{ba}$ & $0.622 \mathrm{bc}$ \\
\hline NEIRA-CAL & $142.8 \mathrm{ed}$ & $14.2 \mathrm{a}$ & $75,2 \mathrm{ba}$ & $0.576 \mathrm{dc}$ \\
\hline SALENTO-QUI & $116.9 \mathrm{ed}$ & $14.0 \mathrm{a}$ & $72.1 \mathrm{~b}$ & $0.555 \mathrm{de}$ \\
\hline RIOSUCIO-CAL & $111.6 \mathrm{ed}$ & $13.7 \mathrm{a}$ & $70.6 \mathrm{bc}$ & $0.536 \mathrm{de}$ \\
\hline IBAGUÉ-TOL & $87.2 \mathrm{e}$ & $13.7 \mathrm{a}$ & $64.5 \mathrm{dc}$ & $0.527 \mathrm{de}$ \\
\hline PALOCAB-TOL & $86.9 \mathrm{e}$ & $13.7 \mathrm{a}$ & $63.6 \mathrm{dc}$ & $0.506 \mathrm{de}$ \\
\hline CALARCÁ-QUI & $83.7 \mathrm{e}$ & $13.6 \mathrm{a}$ & $59.73 \mathrm{~d}$ & $0.491 \mathrm{e}$ \\
\hline
\end{tabular}

Nota: Dentro de una misma columna, promedios con igual letra no difieren estadísticamente

Los caracteres cuantitativos relacionados con el desarrollo de las raíces y los propágulos (rizomas), muestran diferencias significativas entre los datos, como se puede observar en la Tabla 7. 
Tabla 7. Prueba DUNCAN mostrando diferencias significativas entre las accesiones para cada uno de los caracteres cuantitativos relacionados con las raíces del S. sonchifolius.

\begin{tabular}{|c|c|c|c|c|}
\hline \multirow{2}{*}{ ACCESIÓN } & \multicolumn{4}{|c|}{ PROMEDIOS* } \\
\hline & $\begin{array}{c}\text { No. } \\
\text { Raíces }\end{array}$ & $\begin{array}{l}\text { Peso } \\
\text { raíz (g) }\end{array}$ & $\begin{array}{l}\text { Longitud } \\
\text { raíz }(\mathrm{cm})\end{array}$ & $\begin{array}{l}\text { Diámetro } \\
\text { raíz }(\mathrm{cm})\end{array}$ \\
\hline NEIRA-CAL & $13.48 \mathrm{a}$ & $5058.97 \mathrm{a}$ & $17.44 \mathrm{a}$ & $5.76 \mathrm{a}$ \\
\hline CALARCÁ-QUI & $12.09 \mathrm{a}$ & $5138.24 \mathrm{a}$ & $18.09 \mathrm{a}$ & $5.46 \mathrm{a}$ \\
\hline PALOCAB-TOL & $11.72 \mathrm{a}$ & $4977.36 \mathrm{a}$ & $17.57 \mathrm{a}$ & $5.76 \mathrm{a}$ \\
\hline IBAGUÉ-TOL & $11.68 \mathrm{a}$ & $4977.36 \mathrm{a}$ & $17.07 \mathrm{a}$ & $5.82 \mathrm{a}$ \\
\hline SALENTO-QUI & $11.37 \mathrm{a}$ & $4212.67 \mathrm{a}$ & $17.13 \mathrm{a}$ & $4.75 \mathrm{ba}$ \\
\hline DOVIO-VAL & $10.16 \mathrm{a}$ & $4104.72 \mathrm{a}$ & $17.43 \mathrm{a}$ & $5.33 \mathrm{a}$ \\
\hline STA.ROSA-RIS & $9.03 \mathrm{ba}$ & $1295.86 \mathrm{~b}$ & $17.42 \mathrm{a}$ & $3.68 \mathrm{bc}$ \\
\hline TRUJILLO-VAL & $9.03 \mathrm{ba}$ & $1295.86 \mathrm{~b}$ & $17.42 \mathrm{a}$ & $3.68 \mathrm{bc}$ \\
\hline RIO SUCIO-CAL & $8.43 \mathrm{ba}$ & $1295.86 \mathrm{~b}$ & $16.59 \mathrm{a}$ & $6.00 \mathrm{a}$ \\
\hline PEREIRA-RIS & $4.69 \mathrm{~b}$ & $633.58 \mathrm{~b}$ & $15.53 \mathrm{a}$ & $3.48 \mathrm{c}$ \\
\hline
\end{tabular}

*Dentro de una misma columna, promedios con igual letra no difieren estadísticamente

El número de raíces por planta fue muy variable, conformándose tres grupos. El grupo con mayor número de tubérculos de raíz, es el conformado por las accesiones de Neira, Caldas, Palocabildo, Ibagué, Salento y El Dovio. Pereira es el grupo con menor número de tubérculos de raíz (Tabla 7).

Se encontró que el mayor peso referenciado en cada accesión está muy correlacionado con el número de tubérculos, (Neira, Calarcá, Palocabildo, Ibagué, Salento y El Dovio). El peso promedio de estas estuvo por encima de los $4.000 \mathrm{~g}$. y hasta los $5.138 \mathrm{~g}$. por planta. Estos valores nos permiten calcular producciones por hectárea de 28.5 a 36 toneladas por hectárea. Para el caso de las accesiones de más bajo peso, $633.6 \mathrm{~g}$. a $1.295 \mathrm{~g}$. por planta se esperarían rendimientos por de 4.5 a 9.3 toneladas por hectárea. Distancias de siembra de $1.4 \times 1.0 \mathrm{~m}$., para un total de 7.142 plantas por hectárea (Tabla 7).
Cuando se analizaron los promedios por accesión de la longitud de los tubérculos de raíz, no se encontraron diferencias significativas. Sin embargo dentro de cada accesión, la longitud de las raíces es muy variable, desde 10 hasta $30 \mathrm{~cm}$ de longitud. El diámetro de los tubérculos de raíz presentó diferencias significativas entre los promedios de las accesiones, con el mismo patrón. Los tubérculos de raíz más gruesos se encuentran en Neira, Calarcá, Palocabildo, e Ibagué. Las de menor diámetro son las de Pereira, seguidas por las de Santa Rosa y Trujillo (Tabla 7).

A partir del análisis cluster de los caracteres cuantitativos, (Tabla 8) se establecieron tres grupos, dentro de los cuales las accesiones mantienen un grado de similitud muy fuerte: El primer grupo explica el $58.77 \%$ de la variabilidad, a este se relacionaron las accesiones de Calarcá, El Dovio, Ibagué, Palocabildo, Neira y Rio sucio. Estos materiales se caracterizan por mayor peso y diáme- 
tro de los tubérculos de raíz, son de localidades ubicadas entre los 1.120 y 1.693 m.s.n.m., que coinciden con la zona más apta para la producción de café en Colombia, por cuanto puede ser alternativa al cultivo del café, en lugares de baja rentabilidad, sobre todo en las zonas marginales.

Tabla 8. Análisis Clúster de las 10 accesiones de yacón para 21 variables evaluadas.

\begin{tabular}{lcc}
\hline Clúster & Autovalor & $\%$ de Varianza \\
\hline 1 & 7.6133 & 58.77 \\
2 & 3.0924 & 23.87 \\
3 & 2.2490 & 17.36 \\
\hline
\end{tabular}

El grupo dos, integrado por los materiales colectados en Salento, Santa Rosa de Cabal y Trujillo, su variación es explicada en un $23.87 \%$. Las características más sobresalientes son, mayor altura de la planta (148.68 cm en promedio), hojas más anchas y largas, entrenudos más largos y tubérculos de raíz con mayor diámetro. En el tercer grupo, Pereira explica el $17.36 \%$ de la variación. Esta accesión presentó mayor altura, mayor cantidad de hojas, y mayor cantidad de ramas. También es la accesión con menor peso en sus tubérculos, menor diámetro, y mayor número de hojas caídas.
Se realizó análisis factorial, el cual permitió visualizar las contribuciones de cada uno de los descriptores evaluados sobre los ejes factoriales, que mayormente explican la variabilidad. Se encontró que el primer factor (rendimiento en tubérculos de raíz) explica el $42.3 \%$ de la variabilidad, donde el peso de la raíz, el diámetro de la raíz, ancho de la hoja y longitud de la hoja son sus mayores contribuyentes. El segundo factor con un $17.2 \%$ de la variabilidad total, es explicado por las variables longitud de raíz y número de capítulos. En el tercer factor, el aporte de las variables, peso de 100 semillas, altura de la planta y número de hojas en el tallo principal, explicaron el $12.5 \%$ de la variabilidad de la especie

Todo lo anterior puede sugerir, que el yacón ha sido sometido a una selección antrópica, orientada a obtener un tubérculo de raíz de mayor tamaño, plantas de altura media, pocas ramas, hojas, y con baja producción de capítulos florales.

Al hacer un corte transversal en el dendograma derivado del coeficiente de distancia, a la altura de un $\mathrm{R}^{2}$ semiparcial de 0.20, (Figura 1) se puede observar la estructuración de los tres grupos mencionados.

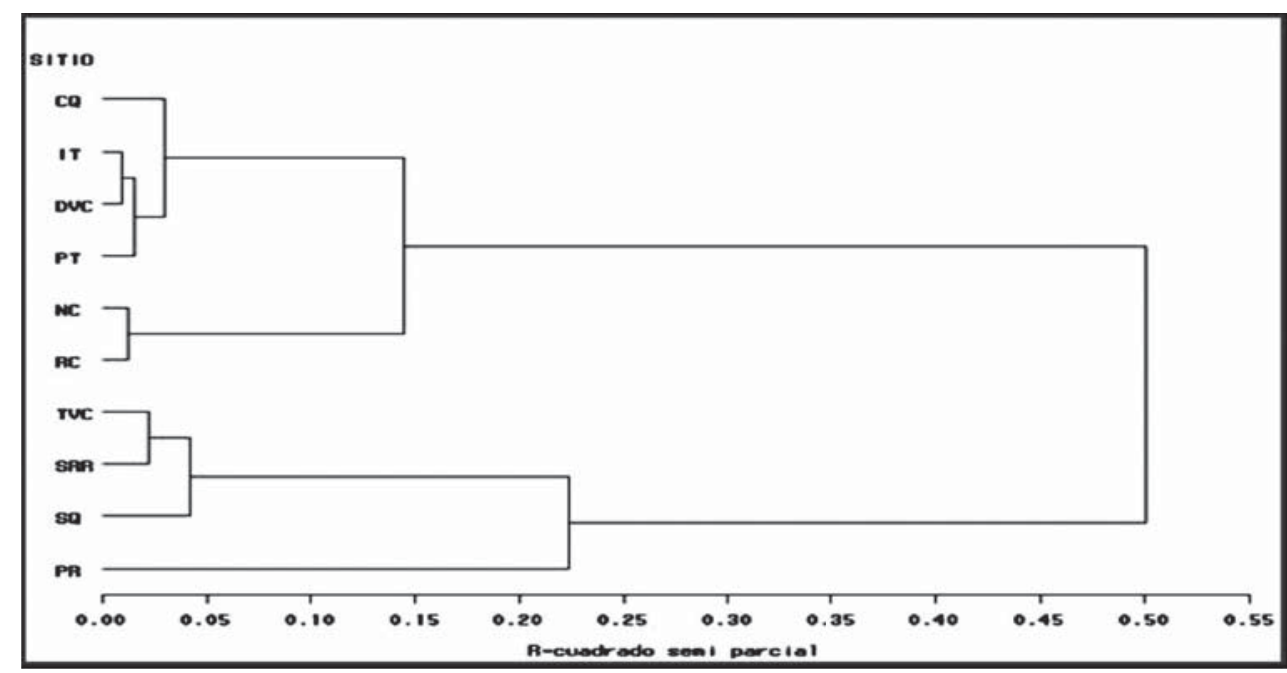

Figura 1. Dendograma de los caracteres cuantitativos de las 10 accesiones de yacón evaluadas. 


\section{Caracteres morfoagronómicos cualitativos evaluados}

Se emplearon ocho descriptores cualitativos de los cuales se evaluaron estadísticamente seis porque los otros mostraron poca variación, como forma (base truncada en el material colectado de lbagué en lugar de hastada) y el color de la flor (igual para todos).
El análisis de correspondencia múltiple, encontró variabilidad entre las accesiones y las clasificó en cuatro grupos. El primer grupo constituido, de accesiones de color del tallo verde oscuro, hojas de color verde claro, color externo de los tubérculos de raíz crema y pulpa blanca, con una explicación del $65.33 \%$ de la variabilidad (Tabla 9).

Tabla 9. Contribuciones parciales de los caracteres morfoagronómicos cualitativos a la variabilidad genética de las accesiones colectadas.

\begin{tabular}{|c|c|c|c|c|c|}
\hline Descriptor & Variaciones & $\begin{array}{c}\operatorname{Dim} 1 \\
(34.4 \%)\end{array}$ & $\begin{array}{c}\operatorname{Dim} 2 \\
(24.1 \%)\end{array}$ & $\begin{array}{c}\operatorname{Dim} 3 \\
(15.2 \%)\end{array}$ & $\begin{array}{c}\operatorname{Dim} 4 \\
(11.0 \%)\end{array}$ \\
\hline \multirow{3}{*}{ Color Tallo } & Verde Claro & 0.2021 & 0.0105 & 0.0027 & 0.0011 \\
\hline & Verde Oscuro & 0.0473 & 0.076 & 0.018 & 0.1325 \\
\hline & Verde Púrpura & 0.0101 & 0.1213 & 0.0293 & 0.1158 \\
\hline \multirow{2}{*}{ Color de la hoja } & Verde Claro & 0.2021 & 0.0105 & 0.0027 & 0.0011 \\
\hline & Verde Oscuro & 0.0505 & 0.0026 & 0.0007 & 0.0003 \\
\hline \multirow{3}{*}{$\begin{array}{l}\text { Color externo } \\
\text { del tubérculo }\end{array}$} & Café crema & 0.0484 & 0.0424 & 0.0611 & 0.1518 \\
\hline & Crema & 0.1082 & 0.0541 & 0.0121 & 0.0014 \\
\hline & Morado & 0.0237 & 0.0014 & 0.2553 & 0.2475 \\
\hline \multirow{4}{*}{$\begin{array}{l}\text { Color Interno } \\
\text { del tubérculo }\end{array}$} & Amarillo & 0.0308 & 0.0037 & 0.2818 & 0.0286 \\
\hline & Amarillo Crema & 0.0042 & 0.2217 & 0.0002 & 0.094 \\
\hline & Blanco & 0.1409 & 0.064 & 0.0346 & 0.0475 \\
\hline & Crema & 0.0037 & 0.021 & 0.2376 & 0.0083 \\
\hline \multirow{2}{*}{$\begin{array}{l}\text { Forma del } \\
\text { Tubérculo }\end{array}$} & Napiforme & 0.0528 & 0.1674 & 0.038 & 0.1138 \\
\hline & Tuberosa & 0.0132 & 0.0419 & 0.0095 & 0.0285 \\
\hline \multirow{2}{*}{ Color de Rizoma } & Púrpura & 0.0124 & 0.0323 & 0.0033 & 0.0056 \\
\hline & Rojizo & 0.0495 & 0.1291 & 0.0131 & 0.0222 \\
\hline
\end{tabular}

Un segundo grupo de accesiones de color del tallo verde púrpura, color de la pulpa del tubérculo de raíz amarillo crema, forma napiforme del tubérculo de raíz y rizomas de color rojizo. La variabilidad explicada por este grupo fue del $63.95 \%$

En el grupo tres, se encuentran las accesiones de color externo del tubérculo de raíz morado; interno amarillo. En este grupo, el $53,71 \%$ de la variabilidad es explicada por estos dos caracteres.

En el cuarto y último grupo están las accesiones con color del tallo verde oscuro, tubérculos de raíz de color externo morado y napiforme (Figuras 10 y 11 ). 


\section{Otras variables morfo-agronómicas evaluadas}

En el proceso de manejo agronómico de las accesiones colectadas y conservadas en el lote de la UNAD, en Dosquebradas Risaralda, se determinaron los tiempos promedios de las fases fisiológicas de las plantas (Tabla 10).

Tabla 10. Duración de las fases fenológicas de las accesiones de Smallanthus sonchifolius colectadas en promedio.

\begin{tabular}{lcc}
\hline Característica & $\begin{array}{c}\text { Tiempo } \\
\text { en días }\end{array}$ & $\begin{array}{c}\text { Tiempo } \\
\text { acumulado desde } \\
\text { la siembra (días) }\end{array}$ \\
\hline $\begin{array}{l}\text { Brotación de } \\
\text { las yemas }\end{array}$ & 15 & 15 \\
Floración & 125 & 150 \\
\hline Cosecha & 250 & 290 \\
\hline
\end{tabular}

\section{Caracterización molecular} de las accesiones de yacón

El ADN extraído se cuantificó en un gel de agarosa al $1 \%$ utilizando tres marcadores de peso molecular: M1 - ADN Lamda 30 ng/ul; M2-ADN Lamda 60 ng/ul y M3-ADN Lamda 90 ng/ul. (Figura 2).

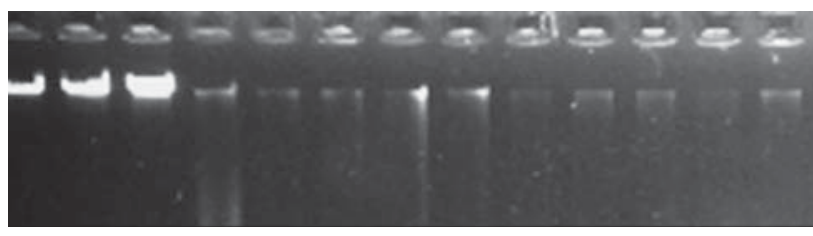

Figura 2. Bandas del ADN total de S. sonchifolius

Los seis iniciadores generaron 86 bandas polimórficas, número suficientemente confiable para la realización de los análisis estadísticos Figura 3.
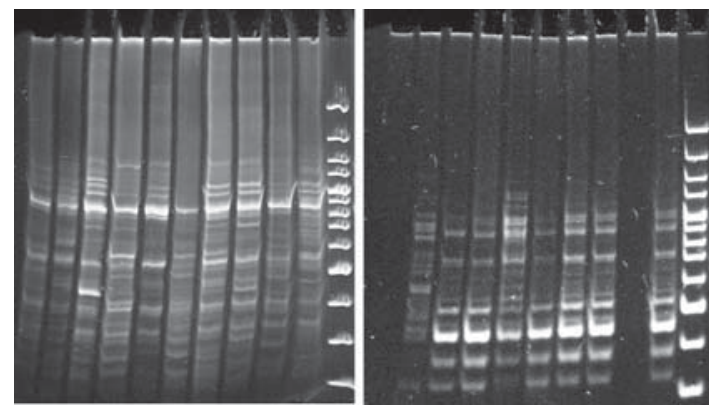

Figura 3. Patrones de bandas generadas por el iniciador CGA (izquierda) y CT (derecha) en las 10 accesiones de $S$. sonchifolius, en geles de acrilamida al $6 \%$.

En el dendograma (Figura 4) se observan cuatro grupos con una similaridad del $68 \%$. En un primer grupo se encuentran las accesiones de Calarcá y Santa Rosa de Cabal. En el segundo las de El Dovio, Pereira, Neira, Rio Sucio y Trujillo, en el tercer grupo Salento y Palocabildo. Finalmente el cuarto está conformado por la accesión de Ibagué.

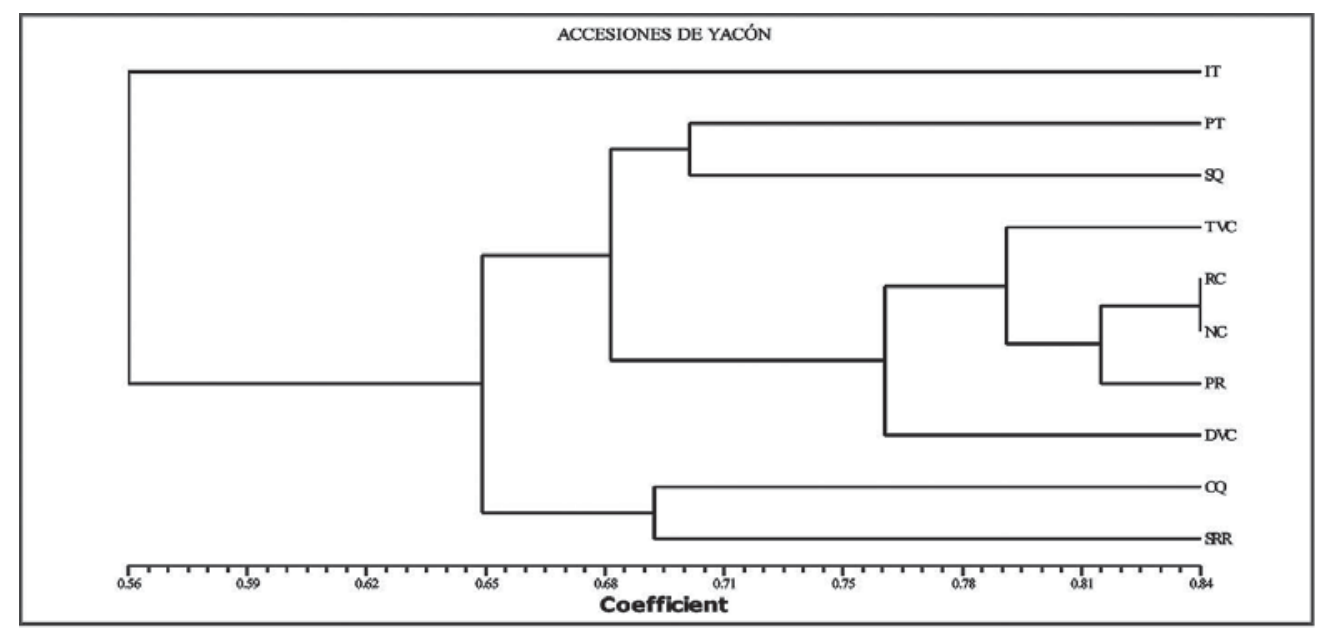

Figura 4. Dendograma de análisis molecular de accesiones de yacón 
El agrupamiento es coherente con ciertos caracteres morfológicos cualitativos de las plantas, como la forma de la hoja. La única accesión diferente, con la base de la hoja truncada, fue la accesión de Ibagué, que el dendograma la clasifica sola en un grupo.

Las accesiones del grupo conformado por El Dovio, Trujillo, Pereira, Neira y Rio Sucio, son plantas con tallos púrpura a verde oscuro y hojas verde oscuro.

El grupo conformado por las accesiones de $\mathrm{Ca}$ larcá y Santa Rosa de Cabal, se caracteriza por poseer tubérculos de raíz con color externo de morado a crema y la pulpa crema. En el grupo conformado por las accesiones de Salento y Palocabildo, su similaridad se encuentra en la forma (napiforme), el color externo crema y el interno amarillo crema del tubérculo (Figura 7 anexo).

\section{Conclusiones}

La planta de yacón presenta un amplio rango altitudinal de adaptación, que va desde los $1.000 \mathrm{~m}$. a los $2.400 \mathrm{~m}$. sobre el nivel del mar, obteniéndose los mayores rendimientos en peso de tubérculos, entre los 1.120 y 1.693 m.s.n.m., localidades de El Dovio, Ibagué, Neira y Rio Sucio, que coinciden con la zonas de producción de café en Colombia, por lo que puede ser una alternativa de diversificación o sustitución del café. Por otra parte, los materiales procedentes de las zonas más frías, son los más adecuados para la producción de forraje.

El análisis de correspondencia múltiple, que evaluó la variabilidad de los materiales en correspondencia con los descriptores morfoagronómicos cualitativos, clasificó los materiales colectados en cuatro grupos, suministrando información que indica que en el germoplasma presente en la ecorregión Eje Cafetero de Colombia existen caracteres importantes, que pueden servir para la selección de posibles parentales con caracteres cualitativos deseables para mejoradores, agricultores y consumidores.
Los datos moleculares diferenciaron cuatro grupos que guardan concordancia con los caracteres morfológicos cualitativos que difieren en color del tallo y hojas, color externo e interno de los tubérculos como de la forma del tubérculo y ratifica que la accesión procedente de Ibagué (Tolima) es diferente.

\section{Literatura citada}

1. CIAT Centro Internacional de Agricultura Tropical. (2004). Curso multi-institucional a distancia sobre conservación ex situ de recursos fitogenéticos. Modulo 4. Cali.: CIAT- IPGRI- Universidad Nacional de Colombia, Sede Palmira, REDCAPA.

2. FAO (Food and Agricultural Organization). (1996). Global Plan of Action for the Conservation and Sustainable Utilization of Plant Genetic Resources for Food and Agriculture. Rome: FAO

3. Ferreira, M. \& Grattapaglia, D. (1998). Introducción al uso de marcadores moleculares en el análisis genético. Brasilia, DF: EMBRAPA-CENARGEN.

4. Grau, A. \& Rea, J. (1997). Yacon Smallanthus sonchifolius (Poepp. \& Endl) H. Robinson. En M. H. Hermann, Andean roots and tubers: Achipa, arracacha, maca and yacon. Promoting the conservation and use of underutilized and neglected crops. 21. (199-242). Rome: Institute of Plant Genetics and Crop Plant Reserch, Gatersleben/Internatioanl Plant Genetics Resources Institute.

5. Hernández, U. (2004). Ensayos de adaptación del yacón en zona cafetera. Tesis de Maestría de Agroecología. Manizales: Universidad de Caldas.

6. Lobo, A. (2006). Recursos genéticos y mejoramiento de frutales andinos: una visión conceptual. Ciencia y Tecnología Agropecuaria. 7(2): 40-54.

7. Manrique, I. H. (2004). Yacón Ficha Técnica. Lima: Centro Internacional de la Papa CIP.

8. Manrique, I., Párraga, A. \& Hermann, M. (2005). Jarabe de yacón: principios y procesamiento. Serie: Conservación y uso de la biodiversidad de raíces y tubérculos andinos: Una década de investigación para el desarrollo (1993-2003) No. 8A. Lima: Centro Internacional de la Papa, Universidad Nacional Daniel Alcides Carrión, Fundación Erbacher, Agencia Suiza para el Desarrollo y la Cooperación.

9. Mayta, P., Payano, J., Peláez, J., Pérez, M., Pichardo, L. \& Puycán, L. (2003). Reducción de la respuesta glicérica posprandial post ingesta de raíz fresca de yacón en sujetos sanos. Ciencia e Investigación Médica Estudiantil Latinoamericana 8: 77-81.

10. Muñoz, J., Murillo, C. \& Murillo, C. (2009). Aplicaciones de la técnica de microsátelites amplificados al azar RAMs (Radom Amplified Microsatellites) en estudios de diversidad génetica. Palmira: Facultad de Ciencias Agropecuarias. Universidad Nacional de Colombia Sede Palmira.

11. Seminario, J., Valderrama, M. \& Manrrique, I. (2003). E Yacón: fundamentos para el aprovechamiento de un recurso promisorio. Lima: Centro Internacional de la Papa (CIP). Universidad Nacional de Cajamarca. Agencia Suiza para el Desarrollo y la Cooperación (COSUDE). 


\section{ANEXOS}

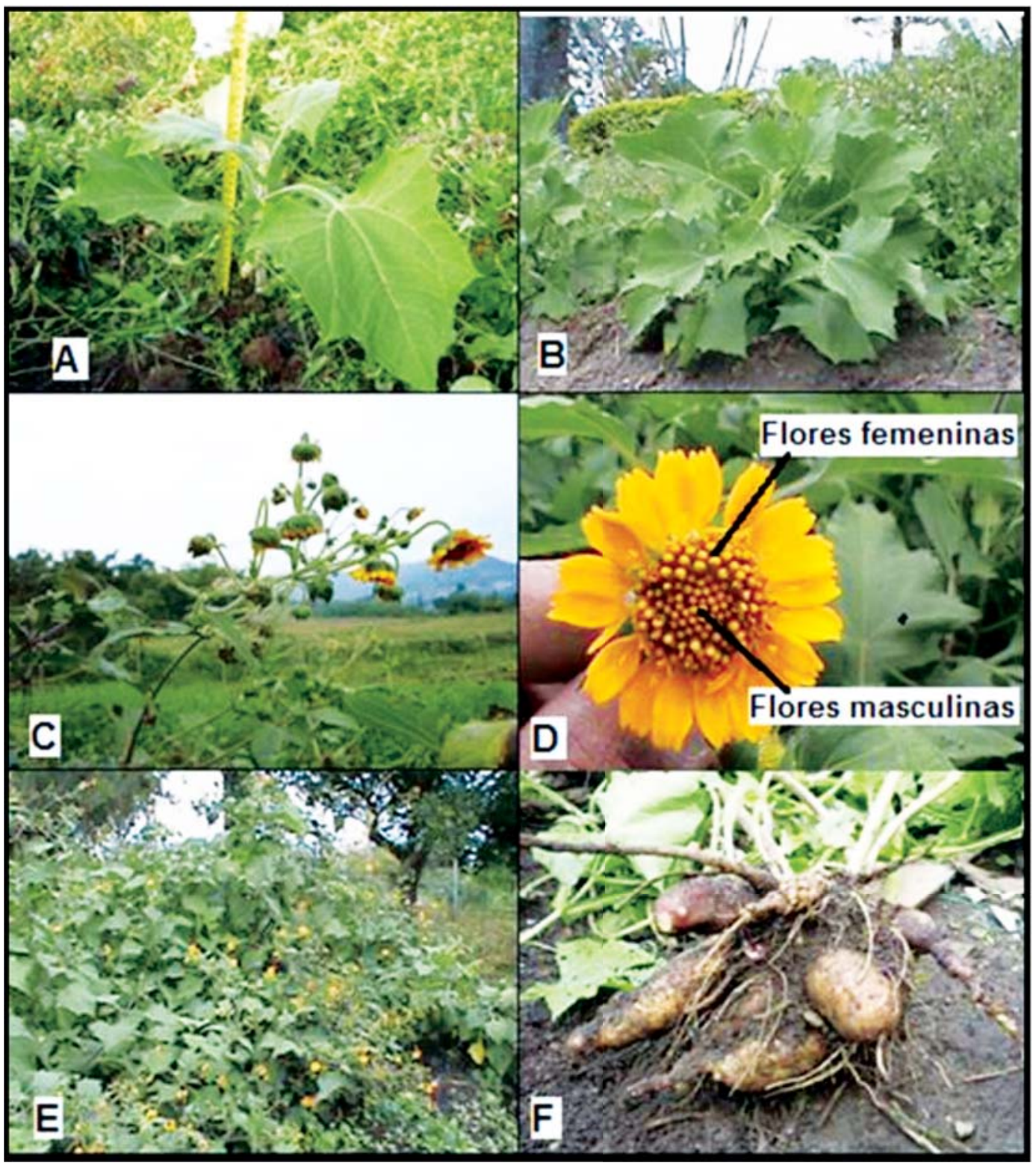

Figura 5. Desarrollo de la planta de yacón a) Una planta de yacón de 45 días de trasplantada,

b) Planta de yacón de 90 días de trasplantada, C) Inflorescencia dicásica. D). Flor compuesta

E) Plantas de yacón en plena floración, F) Raíces reservantes de yacón a la cosecha. 


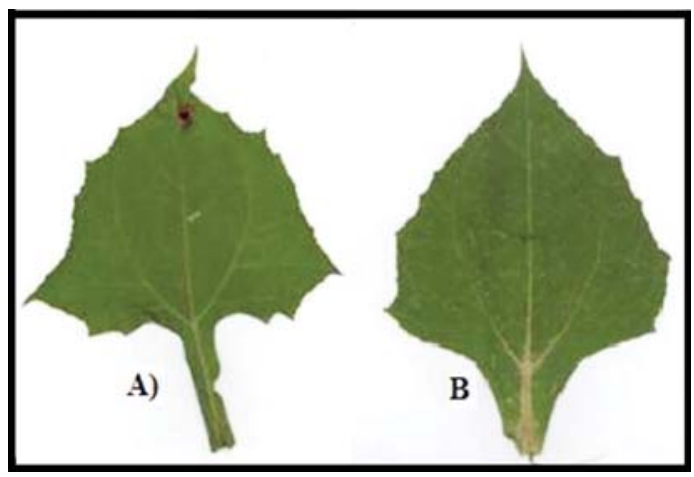

Figura 6. Hojas de yacón. A) Forma triangular, base hastada. B) Forma triangular, base truncada.

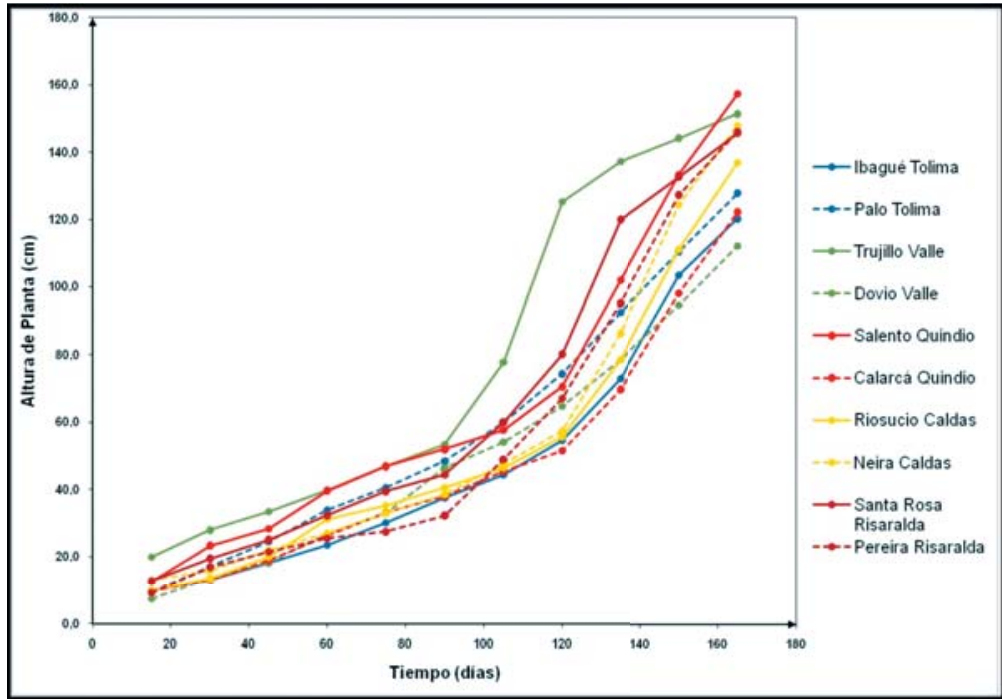

Figura 7. Crecimiento de las plantas de S. sonchifolius por accesión semana tras semana.

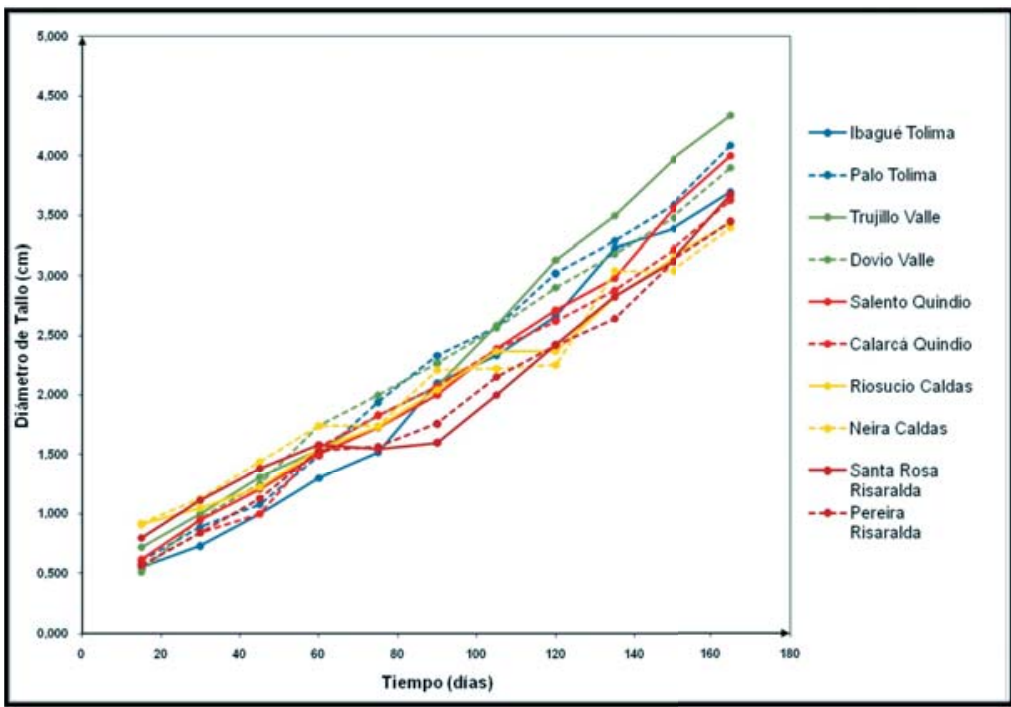

Figura 8. Representación del engrosamiento del diámetro de tallo de las plantas de $S$. sonchifolius, semana tras semana de las 10 accesiones colectadas. 


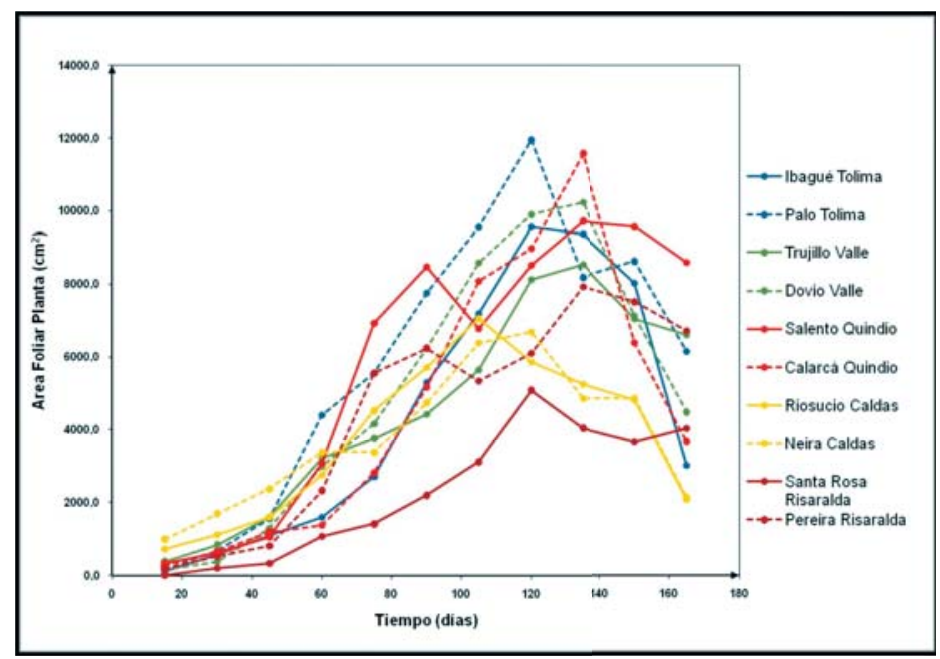

Figura 9. Cambio del área foliar de las accesiones de S. sonchifolius con los días

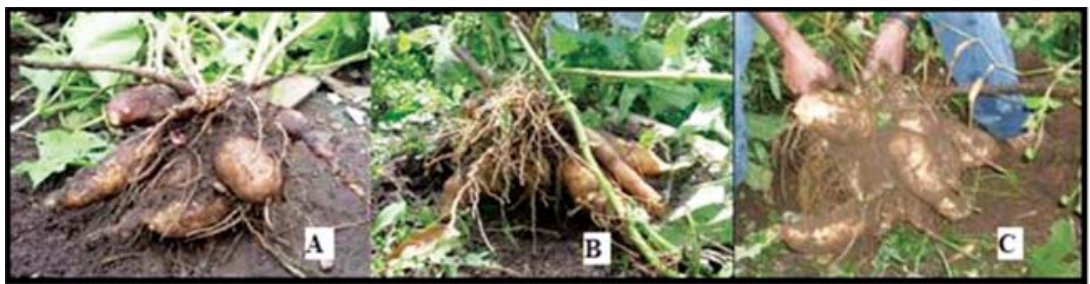

Figura 10. Tubérculos de raíz de S. sonchifolius A) Forma tuberosa, color externo rojizo crema; B) Formas tuberosa, color externo amarillo crema; C) Forma napiforme, color externo crema.

Foto: Autores.

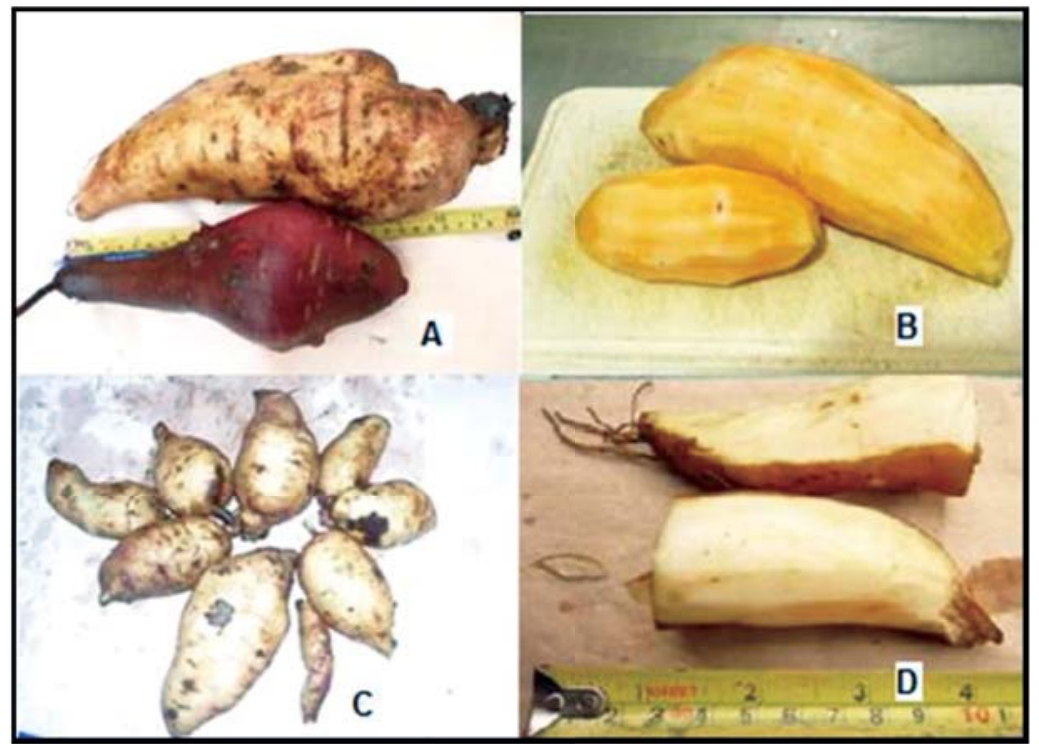

Figura 11. A) Izquierda color externo y forma tuberosa, B) color interno crema, C) forma napiforme y color externo crema, D) color interno amarillo crema. Fuente: autores. 